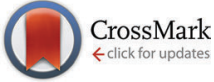

Cite this: Chem. Commun., 2016, 52,6138

Received 4th January 2016, Accepted 31st March 2016

DOI: $10.1039 / c 6 c c 00041 j$

www.rsc.org/chemcomm

\section{Insights into metal-ligand hydrogen transfer: a square-planar ruthenate complex supported by a tetradentate amino-amido-diolefin ligand $\dagger$}

\author{
Demyan E. Prokopchuk, ${ }^{\text {ab }}$ Alan J. Lough, ${ }^{a}$ Rafael E. Rodriguez-Lugo, $\ddagger^{\mathrm{b}}$ \\ Robert H. Morris ${ }^{\star a}$ and Hansjörg Grützmacher* ${ }^{\star b}$
}

\begin{abstract}
A four-coordinate, sixteen-electron $\mathrm{Ru}(0)$ complex containing the tetradentate diamino-diolefin ligand $( \pm$ )-trans- $\mathrm{N}, \mathrm{N}$-bis( $5 \mathrm{H}$-dibenzo$[a, d]$ cyclohepten-5-yl)-1,2-diaminocyclohexane (trop $p_{2}$ dach) has been synthesised. Deprotonation of one amino $\mathrm{N}-\mathrm{H}$ functional group generates an unprecedented four-coordinate ruthenate species which has been characterised in solution and in the solid state. The newly formed ruthenate complex undergoes intramolecular metal-ligand $\mathrm{N}-\mathrm{H}$ addition/elimination in solution to generate a transient diamido ruthenium hydride species, as supported by NMR spectroscopy and density functional theory.
\end{abstract}

In organometallic chemistry, the $\eta^{2}-5 H$-dibenzo[ $[a, d]$-cycloheptenyl $\left(\eta^{2}\right.$-trop) moiety serves as a two-electron $\pi$-donor that can be functionalised with nitrogen or phosphorus atoms bound to the $\mathrm{sp}^{3}$ carbon within the seven-membered ring. ${ }^{1,2}$ In the presence of strong base, amine functionalised trop ligands have been shown to stabilise rhodium, ${ }^{3-8}$ iridium, ${ }^{9-11}$ and ruthenium ${ }^{12-14}$ compounds, much owing to the robust $\pi$-accepting nature of the olefin ligands (Scheme 1). In addition, the $\eta^{2}$-olefin $\mathrm{CH}$ nuclei are sensitive to changes in their electronic environment, making them useful probes into the overall electronic structure.

Complexes containing the trop $_{2}$ dach $($ dach $=(R, R)-1,2$ diaminocyclohexane) and trop ${ }_{2}$ dae (dae $=1,2$-diaminoethane) ligands have been used as catalysts for "green" chemical transformations (Scheme 1). ${ }^{15}$ The iridium complex $\mathbf{B}$, generated by deprotonating $\mathbf{A}$ with strong base, is proposed as an intermediate in the iridium-nitrogen-radical catalyzed oxidation of alcohols, mimicking radical-based metalloenzyme catalysts. ${ }^{11}$ Recently,

\footnotetext{
${ }^{a}$ Department of Chemistry, University of Toronto, 80 Saint George St., Toronto, Ontario M5S3H6, Canada. E-mail: rmorris@chem.utoronto.ca

${ }^{b}$ Department of Chemistry and Applied Biosciences, ETH Zürich, 8093 Zürich, Switzerland. E-mail: hgruetzmacher@ethz.ch

$\dagger$ Electronic supplementary information (ESI) available: Experimental details, DFT calculations. CCDC 1444981-1444983. For ESI and crystallographic data in CIF or other electronic format see DOI: 10.1039/c6cc00041j

\# Current address: Laboratorio de Química Bioinorgánica, Centro de Química, Instituto Venezolano de Investigaciones Científicas (IVIC), Caracas 1020-A, Venezuela. E-mail: rrodriguez@ivic.gob.ve
}

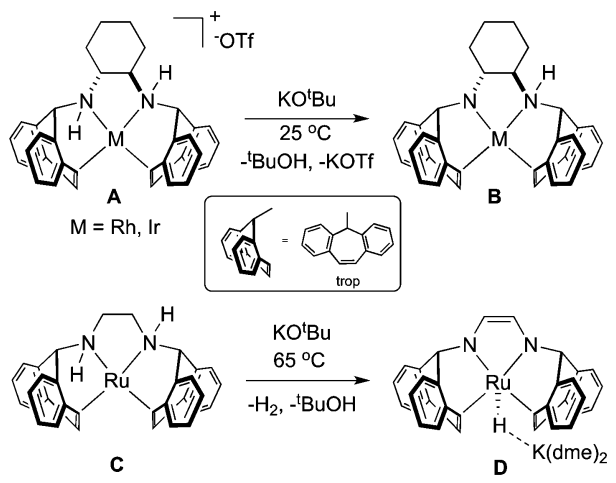

Scheme 1 Reactivity of rhodium and ruthenium amino-olefin ligands with one equivalent strong base. dme $=1,2$-dimethoxyethane.

the anionic ruthenium hydride complex $\mathbf{D}$ was found to be an active catalyst for the formation of $\mathrm{CO}_{2} / \mathrm{H}_{2}$ from 1:1 methanol:water mixtures, with complexes $\mathbf{C}$ and $\mathbf{D}$ being proposed as key intermediates within the catalytic cycle. ${ }^{12}$ In the presence of base, it is proposed that the ligand backbone of zero-valent Ru complex C becomes dehydrogenated and this metal-ligand reactivity/ cooperativity plays a key role in the catalytic methanol dehydrogenation process. In related cases, hydrogenation or dehydrogenation of the PNNP ligand backbone of catalysts can lead to catalyst activation, ${ }^{16-18}$ deactivation, ${ }^{19-21}$ or side reaction ${ }^{22}$ while dehydrogenation of a tridentate PNP ligand allows for the reversible storage/release of two equivalents of hydrogen and change of the spin state. ${ }^{23-26}$

Four coordinate, sixteen-electron $\mathrm{Ru}(0)$ complexes such as $\mathbf{C}$ remain quite rare and related compounds contain bulky and basic phosphines paired with carbonyl or nitrosyl ligands. ${ }^{27-33}$ In our efforts to expand the coordination chemistry and reactivity of ruthenium amino-olefin complexes, we report the synthesis and characterization of tetradentate amino-olefin $\mathrm{Ru}(0)$ and amido-olefin ruthenate complexes (Scheme 2). Our experimental observations and calculations support the ease with which hydrogen can migrate between metal and ligand, which might be operative in the mechanism of methanol dehydrogenation using complexes $\mathbf{C}$ and/or $\mathbf{D}$. 

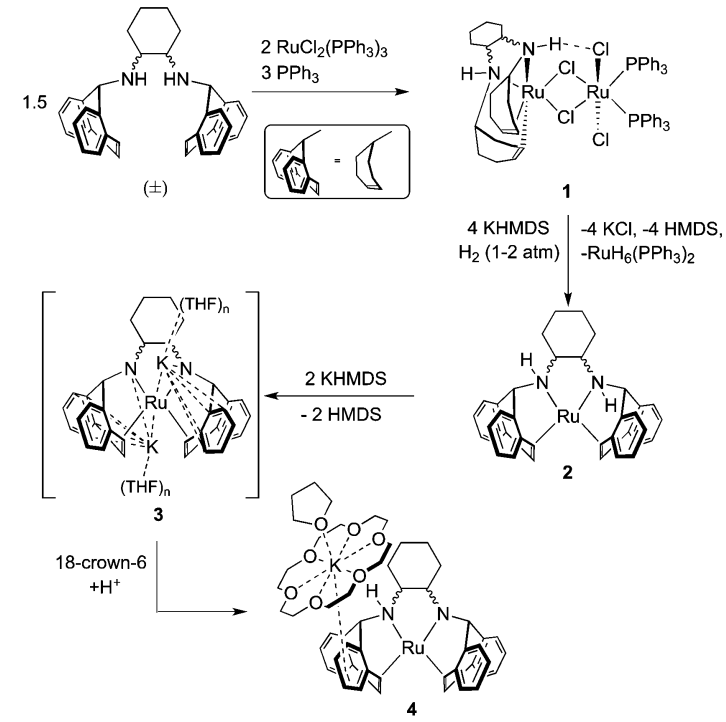

Scheme 2 Synthesis of compounds 1-4

Upon reaction of two equivalents of $\mathrm{RuCl}_{2}\left(\mathrm{PPh}_{3}\right)_{3}$ with an excess of ( \pm )-trans- $N, N$-bis(5H-dibenzo[a,d]cyclohepten-5-yl)-1,2diaminocyclohexane $(( \pm) \text { trop } 2 \text { dach })^{34}$ and $\mathrm{PPh}_{3}$, the chloro-bridged bimetallic species 1 precipitates from solution as an analytically pure powder which is insoluble in common organic solvents (Scheme 2). In lieu of solution-state analysis, 1 was characterised by solid-state CP/MAS NMR and single crystal X-ray diffraction (Scheme 1 and Fig. S1, ESI $\dagger$ ). The solid-state ${ }^{13} \mathrm{C}\left\{{ }^{1} \mathrm{H}\right\}$ NMR spectrum of 1 reveals three groups of signals consistent with a coordinated trop ${ }_{2}$ dach ligand while the ${ }^{31} \mathrm{P}$ NMR contains a broad resonance centred at $53.8 \mathrm{ppm}$, also consistent with coordinated $\mathrm{PPh}_{3}$ (see the ESI $\dagger$ ).

When dimer 1 is heated in the presence of four equivalents of the strong base potassium hexamethyldisilazide (KHMDS) under a hydrogen atmosphere, the pale pink suspension turns deep orange. Analysis of the crude products by ${ }^{1} \mathrm{H}$ and ${ }^{31} \mathrm{P}$ NMR indicates the presence of two compounds, one whose hydride chemical shift matches the known polyhydride species $\mathrm{RuH}_{6}\left(\mathrm{PPh}_{3}\right)_{2}{ }^{35-37}$ and the other being the zero-valent Ru complex Ru(trop 2 dach) (2, Scheme 1). These products form by a series of steps involving, in no proven order, the precipitation of potassium chloride, the heterolytic splitting of dihydrogen at ruthenium, formation of ruthenium hydrides and hexamethyldisilazane, and the cleavage of the dimer to give the two monometallic products.

Complex 2 was characterised by NMR spectroscopy and single crystal X-ray diffraction (Fig. 1, left). The complex resides in a distorted square planar geometry with one molecule of

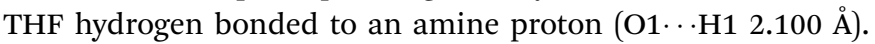
The Ru-centroid bond distances $(\mathrm{Ru} 1-\mathrm{ct} 1=1.980(4)$, Ru1-ct2 = 1.973(5) A) are significantly shorter than in 1 and the metrical parameters are similar to those of complex $\mathbf{C}$. $^{12}$

In the presence of KHMDS and heat, complex 2 does not behave in a manner similar to $\mathbf{C}$, which undergoes dehydrogenation at the ethylene bridge between the nitrogen atoms. ${ }^{12}$ With two or more equivalents strong base, we observe that the backbone of 2 remains intact, generating a symmetrical species containing

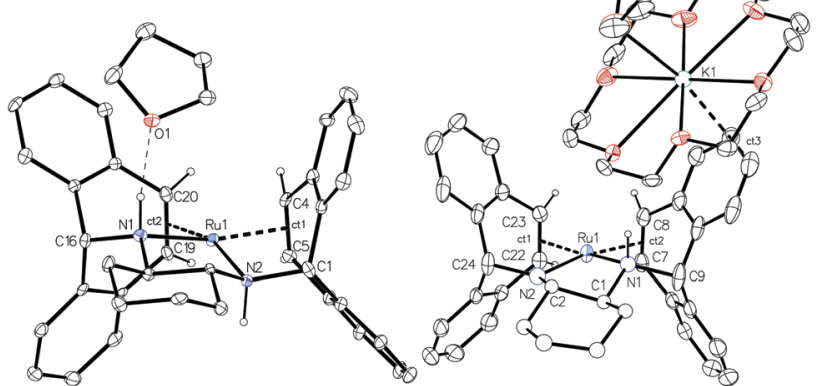

Fig. 1 Molecular structures of 2 (left) and $\mathbf{4}$ (right) with 30\% probability ellipsoids. Only a single enantiomer is shown and most hydrogen atoms have been omitted for clarity. Distances $(\AA)$ and angles $\left({ }^{\circ}\right)$ 2: Ru1-N1 2.131(4), Ru1-N2 2.129(3), Ru1-ct1 1.980(4), Ru1-ct2 1.973(5), C4-C5 1.423(7), C19-C20 1.435(7), O1․H1 2.100; N1-Ru1-N2 82.0(2), ct1-Ru1-ct2 98.30(2), N1-Ru1-ct2 92.18(2), N2-Ru1-ct1 92.18(2), N1-Ru1-ct1 163.51(2), N2-Ru1-ct2 162.37(2). 4: Ru1-N1 2.091(5), Ru1-N2 1.995(4), Ru1-ct1 1.992(4), Ru1-ct2 1.997(3), K1․ct3 3.221(5), C7-C8 1.445(5), C22-C23 1.435(5); N1-Ru1-N2 80.2(2), ct1-Ru1-ct2 98.73(2), N1-Ru1-ct2 90.90(2), N2-Ru1-ct1 90.98(2), N1-Ru1-ct1 167.65(2), N2-Ru1-ct2 169.07(2).

$\mathrm{CH}_{\text {dach }}$ NMR resonances at 2.09 ppm $\left({ }^{1} \mathrm{H}\right)$ and $74.14 \mathrm{ppm}\left({ }^{13} \mathrm{C}\right)$ (see $\mathrm{ESI} \dagger)$. The same product is observed using the strong base $\mathrm{KO}^{t} \mathrm{Bu}$, however reactions were cleaner when using KHMDS. We propose that the solution state structure is the doubly deprotonated $[\mathrm{K}]_{2}\left[\mathrm{Ru}\left(\mathrm{trop}_{2} \text { dach-2H)].(THF) }\right)_{n}(3)\right.$, an intimate ion-paired structure that might prevent backbone dehydrogenation. Diamidodiolefin rhodium ${ }^{38}$ and nickel ${ }^{39}$ complexes containing similar potassium-nitrogen interactions have been structurally characterised while potassium-nitrogen ion pairing has also been observed in other metal-amido type systems. ${ }^{40-42}$ A square planar, dianionic $\mathrm{Ru}(0)$ complex $\left[\mathrm{Li}(\mathrm{THF})_{3}\right]_{2}\left[\mathrm{Ru}\left(\mathrm{P}_{2}\right)_{2}\right]$ with $2,2^{\prime}$ biphosphinine $\left(\mathrm{P}_{2}\right)$ ligands was reported where both lithium cations sit directly on top of ruthenium. ${ }^{43}$

Crystallization of solutions containing 3 in the presence of 18-crown-6 (18c6) consistently resulted in reprotonation of one amido nitrogen atom, generating large brown-black crystals of the four-coordinate amidoruthenate complex [K(18c6.THF)]$\left[\mathrm{Ru}\left(\right.\right.$ trop $_{2}$ dach-H)].THF (4, Fig. 1). The source of proton could be the hexamethyldisilazane that is generated in the preparation of 3, however its origin is still unclear. The molecular structure shows a shortening of the $\mathrm{Ru}-\mathrm{N}_{\text {amido }}$ bond by about $0.1 \AA$ (1.995(4) $\AA$ ) with respect to $\mathrm{Ru}-\mathrm{N}_{\text {amino }}(2.091(5) \AA)$, with the $\mathrm{N}_{\text {amido }}$ atom approaching a planar coordination geometry $\left(\Sigma^{\circ}=354.8^{\circ}\right)$. The complex $\left[\mathrm{Ru}(\mathrm{NO})\left(\mathrm{PtBu}_{2} \mathrm{CH}_{2} \mathrm{SiMe}_{2} \mathrm{NSiMe}_{2} \mathrm{CH}_{2} \mathrm{PtBu}_{2}\right)\right]$ has a $\mathrm{Ru}-\mathrm{N}_{\text {amido }}$ distance of $2.070(2) \AA{ }^{44}$ significantly longer than Ru1-N2 1.995(4) in 4. The $\mathrm{K}(18 \mathrm{c} 6)$ cation is capped with one THF molecule and weakly bound to one of the benzo groups on

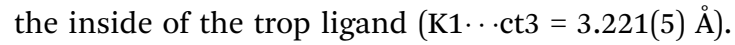

DFT-calculated (M06/TZVP/TZVPFit) ${ }^{45}$ molecular orbital (MO) and Atomic Polar Tensor (APT) charge analysis of $\mathbf{2}$ and $\mathbf{4}$ are presented in Fig. 2. In line with the Dewar-Chatt-Duncanson model for metal-olefin binding, ${ }^{46}$ the degenerate MOs at $-0.20 \mathrm{eV}$ for complex 2 predominantly consist of stabilizing interactions between the $\mathrm{d}_{x z} / \mathrm{d}_{y z}$ and $\pi^{*}$ atomic orbitals (AOs) of the $\eta^{2}$-trop olefin ligands. The next two MOs at -0.18 and $-0.16 \mathrm{eV}$ consist of nonbonding 


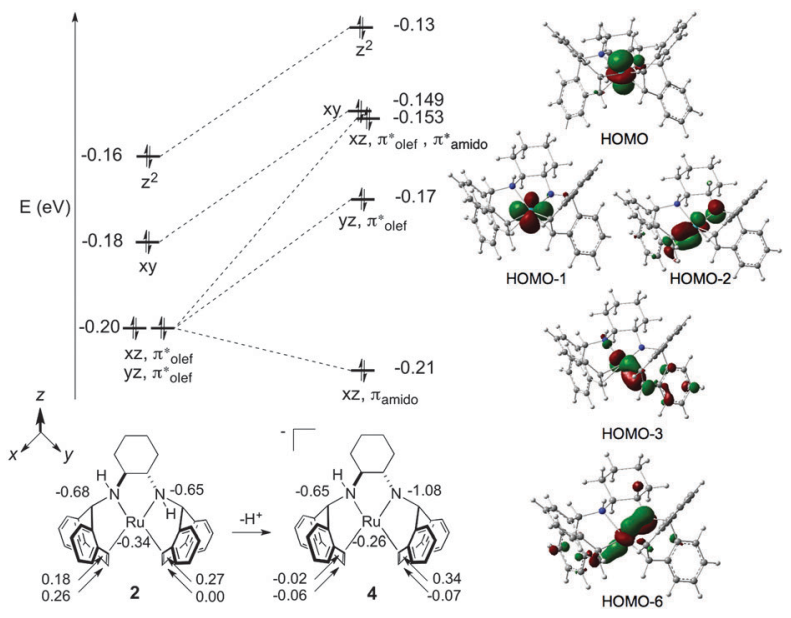

Fig. 2 Top left: Partial orbital energy diagram on going from 2 to $\mathbf{4}$ with relative orbital energies given in eV. Right: Kohn-Sham orbitals of $\mathbf{4}$ (isovalue $=0.06$ ). Bottom left: Selected APT charges of $\mathbf{2}$ and $\mathbf{4}$ given in ESU.

electrons of $\mathrm{d}_{x y}$ and $\mathrm{d}_{z^{2}}$ parentage. Evaluation of the APT charges on the ruthenium, nitrogen, and $\eta^{2}$-trop carbon atoms of 2 reveals that the $\mathrm{N}$ atoms bear the most negative atomic charges ( -0.68 and -0.65 ESU). The calculated and experimental metrical parameters for $\mathbf{2}$ and $\mathbf{4}$ are in good agreement (see ESI $\dagger$ ).

Amino-amido complex 4 has two occupied MOs, HOMO-2 and HOMO-6, that participate in a three-centre-four-electron $\mathrm{N}_{\text {amido }}-\mathrm{Ru}$-olefin "push-pull" $\pi-\pi^{*}$ interaction (Fig. 2, right). ${ }^{38,47,48}$ The electron pair in HOMO-6 is stabilised by an $\mathrm{N}_{\text {amido }}$ bonding interaction with the $\mathrm{d}_{x z} \mathrm{AO}$, and HOMO-2 consists of a backbonding interaction between the $\mathrm{d}_{x z}$ and $\eta^{2}$-trop antibonding orbitals with a strong $\mathrm{N}_{\text {amido }}-\mathrm{d}_{x z}$ antibonding contribution. The APT charges show that there is significant charge localization on $\mathrm{N}_{\text {amido }}(-1.08 \mathrm{ESU})$, which is accompanied by an increase in negative charge at the $\eta^{2}$-trop carbon atoms trans to the $\mathrm{N}_{\text {amido }}$ moiety $(-0.02$ and -0.06 , respectively). Note that there is little change in the atomic charge at ruthenium on going from 2 to 4 , indicating that the ligand framework absorbs the additional charge upon deprotonation. ${ }^{49}$

Complex 4 is highly sensitive to solvent conditions - it decomposes in pure DMSO and is insoluble in ethereal and hydrocarbon solvents. However, the addition of DMSO- $\mathrm{d}_{6}$ to crystals of 4 immersed in $\mathrm{THF}-\mathrm{d}_{8}$ resulted in its dissolution and allowed for its complete 1D and 2D NMR characterization. The ${ }^{1} \mathrm{H}$ NMR chemical shifts of the $\eta^{2}$-trop $\mathrm{CH}_{\text {olef }}$ protons in 4 appear as four doublets ranging from 2.6 to $0.9 \mathrm{ppm}$, far upfield with respect to the free trop ${ }_{2}$ dach ligand $(\delta=6.8,6.6 \mathrm{ppm})^{34}$ and $\mathrm{Rh} / \mathrm{Ir}$ complexes A and B (see Table S1, ESI $\dagger$ for comparison). The $\mathrm{N}-\mathrm{H}$ proton resonance, which would be expected between 4 and 6 ppm, ${ }^{11,38}$ could not be located anywhere between +14 and $-30 \mathrm{ppm}$. Furthermore, ${ }^{1} \mathrm{H}-{ }^{1} \mathrm{H}$ NOESY NMR experiments reveal strong and well-resolved EXSY cross-peaks, indicating dynamic chemical exchange in solution (see ESI $\dagger$ ). In addition to aromatic region exchange cross-peaks, there are an additional eight pairs of exchange cross-peaks in total, arising from the sixteen protons that belong to the cyclohexyl ring, trop- $\mathrm{CH}_{\text {benzyl }}$ positions,

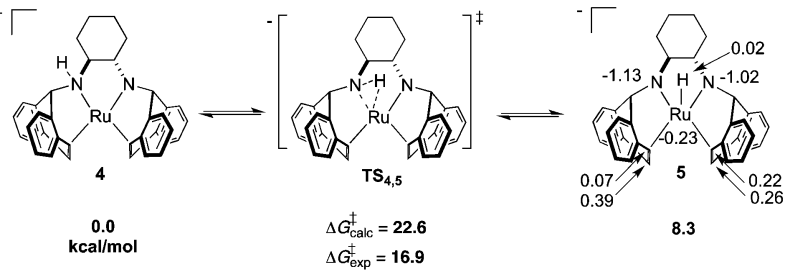

Scheme 3 DFT calculated free energies (relative to 4 ) for proposed $\mathrm{N}-\mathrm{H}$ addition/elimination reactions in solution. Energies are presented in $\mathrm{kcal} \mathrm{mol}{ }^{-1}$ and APT charges in ESU are also shown for $\mathbf{5}$.

and $\eta^{2}$-trop olefinic protons. Further studies of $\mathbf{4}$ by variable temperature NMR were hindered by its high reactivity and the lack of a suitable solvent. However, an estimate of the rate constant based on a simple two-site chemical exchange process ${ }^{50,51}$ is $2.7 \pm 0.4 \mathrm{~s}^{-1}$, with $\Delta G^{\ddagger}=16.9 \pm 0.1 \mathrm{kcal} \mathrm{mol}^{-1}$ (see the ESI $\dagger$ ).

As determined by DFT calculations, we propose that complex 4 is a chemically non-innocent ${ }^{52}$ species undergoing dynamic $\mathrm{N}-\mathrm{H}$ addition/elimination, generating a transient diamido ruthenium hydride intermediate (Scheme 3 ). A cyclic three-membered transition state has been located $\left(\Delta G^{\ddagger}\left(\mathbf{T S}_{\mathbf{4}, \mathbf{5}}\right)=\right.$ $22.6 \mathrm{kcal} \mathrm{mol}^{-1}$ ), generating the distorted square pyramidal complex 5 which can be formally viewed as a $\mathrm{Ru}(\mathrm{II})$ hydridodiamido complex. Similar to 4, APT analysis of 5 shows that the charge at ruthenium remains unperturbed while the amido nitrogens absorb the negative charge, further indicating the "spectator-like" nature of the metal centre. Although the calculated free energy is substantially higher than the estimated free energy from experiment, all other calculated transition state structures were even higher in energy (Scheme S1, ESI $\dagger$ ). Inclusion of one molecule of THF or DMSO increases the ground state energies and transition state barriers for insertion/ elimination, suggesting that solvent plays no significant role within the inner coordination sphere. The TS barrier on going from 5 to the tautomer of $\mathbf{4}$, formed by a hydrogen shift to the other nitrogen, is higher in free energy than $\mathbf{T S}_{\mathbf{4}, \mathbf{5}}$ by $5.5 \mathrm{kcal} \mathrm{mol}^{-1}$. However a fluxional rearrangement of 5 that brings the hydride to the opposite side of the square plane, followed by an $\mathrm{H}$ shift to the other nitrogen via the symmetry-related $\mathbf{T S}_{\mathbf{4 , 5}}$ would explain the features of the EXSY spectrum. Two isomers resulting from $\beta$-hydride elimination were also ruled out due to their high ground state free energies. Furthermore, recent calculations show that a similar three-membered insertion transition state $\mathbf{T S}_{\mathbf{4}, \mathbf{5}}$ is a proposed key step during methanol dehydrogenation using catalyst $\mathbf{C}$ (Scheme 1$).{ }^{53}$

In summary, we have presented a low-coordinate $\mathrm{Ru}(0)$ complex based on a diamino-diolefin ligand with a functionalised diaminocyclohexyl backbone. In stark contrast to the trop $\mathrm{p}_{2}$ dae $\mathrm{Ru}(0)$ complex $\mathbf{C}$, reactions with base only deprotonate at the amine positions, allowing for the isolation and structural characterization of an unprecedented four-coordinate ruthenate complex. Such a species is reminiscent of its valence isoelectronic rhodium $^{6}$ and iridium ${ }^{11}$ analogues, but NMR and DFT experiments indicate that the $\mathrm{N}-\mathrm{H}$ moiety is non-innocent in solution. The observed solution state behaviour of $\mathbf{4}$ provides some evidence into how $\mathbf{C}$ might participate in transferring hydrogen 
between the metal and ligand during catalytic methanol dehydrogenation. Future efforts will be directed towards synthesizing other functionalised trop $\mathrm{p}_{2}$ (diamine) derivatives and investigating these compounds for the catalytic dehydrogenation of alcohols.

D. E. P. thanks the NSERC Michael Smith Foreign Study Supplement (MSFSS) for funding and H. G. for hosting. R. H. M. thanks NSERC for a Discovery Grant. The authors wish to acknowledge the Canadian Foundation for Innovation, project number 19119, and the Ontario Research Fund for funding of the Centre for Spectroscopic Investigation of Complex Organic Molecules and Polymers. D. E. P. also thanks Dr Darcy Burns and Sergiy Nokhrin for assistance with NMR experiments, Molly Sung for sample preparation/analysis, and Dr Monica Trincado for useful discussions.

\section{Notes and references}

1 J. Harmer, G. Frison, M. Rudolph, H. Schönberg, S. Deblon, P. Maire, S. Boulmaaz, F. Breher, C. Bohler, H. Ruegger, A. Schweiger and H. Grützmacher, Perspectives in Organometallic Chemistry, The Royal Society of Chemistry, 2003, pp. 222.

2 C. Defieber, H. Grützmacher and E. M. Carreira, Angew. Chem., Int. Ed., 2008, 47, 4482.

3 H. Schönberg, S. Boulmaâz, M. Wörle, L. Liesum, A. Schweiger and H. Grützmacher, Angew. Chem., Int. Ed., 1998, 37, 1423.

4 T. Buttner, F. Breher and H. Grutzmacher, Chem. Commun., 2004, 2820.

5 P. Maire, T. Büttner, F. Breher, P. Le Floch and H. Grützmacher, Angew. Chem., Int. Ed., 2005, 44, 6318.

6 P. Maire, M. Königsmann, A. Sreekanth, J. Harmer, A. Schweiger and H. Grützmacher, J. Am. Chem. Soc., 2006, 128, 6578.

7 G. Mora, S. van Zutphen, C. Thoumazet, X. F. Le Goff, L. Ricard, H. Grutzmacher and P. Le Floch, Organometallics, 2006, 25, 5528.

8 T. Zweifel, J.-V. Naubron and H. Grützmacher, Angew. Chem., Int. Ed., 2009, 48, 559.

9 P. Maire, S. Deblon, F. Breher, J. Geier, C. Böhler, H. Rüegger, H. Schönberg and H. Grützmacher, Chem. - Eur. J., 2004, 10, 4198.

10 E. Piras, F. Läng, H. Rüegger, D. Stein, M. Wörle and H. Grützmacher, Chem. - Eur. J., 2006, 12, 5849.

11 M. Königsmann, N. Donati, D. Stein, H. Schönberg, J. Harmer, A. Sreekanth and H. Grützmacher, Angew. Chem., Int. Ed., 2007, 46, 3567.

12 R. E. Rodríguez-Lugo, M. Trincado, M. Vogt, F. Tewes, G. SantisoQuinones and H. Grützmacher, Nat. Chem., 2013, 5, 342.

13 G. Santiso-Quinones, R. Rodriguez-Lugo, V. Sacchetti and H. Grutzmacher, Acta Crystallogr., Sect. C: Cryst. Struct. Commun., 2013, 69, 1421.

14 G. Santiso-Quinones and R. E. Rodriguez-Lugo, Acta Crystallogr., Sect. C: Cryst. Struct. Commun., 2013, 69, 859.

15 M. Trincado, D. Banerjee and H. Grutzmacher, Energy Environ. Sci., 2014, 7, 2464.

16 A. A. Mikhailine, M. I. Maishan, A. J. Lough and R. H. Morris, J. Am. Chem. Soc., 2012, 134, 12266.

17 W. Zuo, A. J. Lough, Y. F. Li and R. H. Morris, Science, 2013, 342, 1080.

18 R. H. Morris, Acc. Chem. Res., 2015, 48, 1494.

19 F. N. Haque, A. J. Lough and R. H. Morris, Inorg. Chim. Acta, 2008, $361,3149$.
20 P. O. Lagaditis, P. E. Sues, A. J. Lough and R. H. Morris, Dalton Trans., 2015, 44, 12119.

21 W. Zuo, D. E. Prokopchuk, A. J. Lough and R. H. Morris, ACS Catal., 2016, 6, 301.

22 R. Langer, I. Fuchs, M. Vogt, E. Balaraman, Y. Diskin-Posner, L. J. W. Shimon, Y. Ben-David and D. Milstein, Chem. - Eur. J., 2013, 19, 3407.

23 S. Schneider, J. Meiners and B. Askevold, Eur. J. Inorg. Chem., 2012, 412.

24 B. Askevold, H. W. Roesky and S. Schneider, ChemCatChem, 2012, 4, 307.

25 M. Kinauer, M. G. Scheibel, J. Abbenseth, F. W. Heinemann, P. Stollberg, C. Wurtele and S. Schneider, Dalton Trans., 2014, 43, 4506.

26 B. Askevold, M. M. Khusniyarov, W. Kroener, K. Gieb, P. Müller, E. Herdtweck, F. W. Heinemann, M. Diefenbach, M. C. Holthausen, V. Vieru, L. F. Chibotaru and S. Schneider, Chem. - Eur. J., 2015, 21, 579.

27 M. A. A. F. D. C. T. Carrondo, B. N. Chaudret, D. J. Cole-Hamilton, A. C. Skapski and G. Wilkinson, J. Chem. Soc., Chem. Commun., 1978, 463.

28 M. Ogasawara, S. A. Macgregor, W. E. Streib, K. Folting, O. Eisenstein and K. G. Caulton, J. Am. Chem. Soc., 1995, 117, 8869.

29 R. Flügel, B. Windmüller, O. Gevert and H. Werner, Chem. Ber., 1996, 129, 1007.

30 M. Ogasawara, S. A. Macgregor, W. E. Streib, K. Folting, O. Eisenstein and K. G. Caulton, J. Am. Chem. Soc., 1996, 118, 10189.

31 D. Huang, W. E. Streib, E. Odile and K. G. Caulton, Organometallics, 2000, 19, 1967.

32 T. Gottschalk-Gaudig, J. C. Huffman, H. Gérard, O. Eisenstein and K. G. Caulton, Inorg. Chem., 2000, 39, 3957.

33 H. Salem, L. J. W. Shimon, Y. Diskin-Posner, G. Leitus, Y. Ben-David and D. Milstein, Organometallics, 2009, 28, 4791.

34 P. Maire, F. Breher, H. Schönberg and H. Grützmacher, Organometallics, 2005, 24, 3207.

35 B. Chaudret, J. Devillers and R. Poilblanc, J. Chem. Soc., Chem. Commun., 1983, 641.

36 B. Chaudret, J. Devillers and R. Poilblanc, Organometallics, 1985, 4, 1727.

37 K. Abdur-Rashid, D. G. Gusev, A. J. Lough and R. H. Morris, Organometallics, 2000, 19, 1652.

38 P. Maire, F. Breher and H. Grützmacher, Angew. Chem., Int. Ed., 2005, 44, 6325.

39 M. Vogt, PhD Dissertation, ETH Zürich, Nr. 19295, 2010.

40 D. Song and R. H. Morris, Organometallics, 2004, 23, 4406.

41 P. Cui, T. P. Spaniol and J. Okuda, Organometallics, 2013, 32, 1176.

42 J. M. John, S. Takebayashi, N. Dabral, M. Miskolzie and S. H. Bergens, J. Am. Chem. Soc., 2013, 135, 8578.

43 P. Rosa, N. Mézailles, L. Ricard, F. Mathey, P. Le Floch and Y. Jean, Angew. Chem., Int. Ed., 2001, 40, 1251.

44 A. Walstrom, M. Pink, H. Fan, J. Tomaszewski and K. G. Caulton, Inorg. Chem., 2007, 46, 7704.

45 For additional information on the DFT methods used, see the ESI $\dagger$. 46 D. M. P. Mingos, J. Organomet. Chem., 2001, 635, 1.

47 D. Conner, K. N. Jayaprakash, T. B. Gunnoe and P. D. Boyle, Inorg. Chem., 2002, 41, 3042.

48 B. Askevold, A. Friedrich, M. R. Buchner, B. Lewall, A. C. Filippou, E. Herdtweck and S. Schneider, J. Organomet. Chem., 2013, 744, 35.

49 Cyclic voltammetry of 2 and 4 revealed multiple weak and irreversible redox events.

50 C. L. Perrin and T. J. Dwyer, Chem. Rev., 1990, 90, 935.

51 J. Jeener, B. H. Meier, P. Bachmann and R. R. Ernst, J. Chem. Phys., 1979, 71, 4546.

52 L. A. Berben, B. de Bruin and A. F. Heyduk, Chem. Commun., 2015, $51,1553$.

53 H. Li and M. B. Hall, J. Am. Chem. Soc., 2015, 137, 12330. 